06

\title{
Исследование диффузионного соединения стали 45 через прессованный порошковый слой никеля
}

\author{
() Г.М. Зеер, ${ }^{1}$ Е.Г. Зеленкова, ${ }^{1}$ В.И. Темных, ${ }^{1}$ А.М. Токмин, ${ }^{1}$ А.А. Шубин, ${ }^{1}$ Ю.П. Королёва, ${ }^{1}$ А.А. Михеев ${ }^{2}$ \\ ${ }^{1}$ Сибирский фредеральный университет, \\ 660041 Красноярск, Россия \\ ${ }^{2}$ Сибирский государственный аэрокосмический университет им. акад. М.Ф. Решетнева, \\ 660014 Красноярск, Россия \\ e-mail: g-zeer@mail.ru
}

(Поступило в Редакцию 5 мая 2017 г.)

Исследованы микроструктура переходной зоны и порошковой прослойки, концентрационное распределение химических элементов по ширине диффузионного соединения и микротвердость слоистых композитов сталь 45-прессованная порошковая прослойка $\mathrm{Ni}$ - сталь 45, полученных диффузионной сваркой. Показано, что для получения качественного соединения оптимальной является прослойка, полученная при давлении прессования $500 \mathrm{MPa}$, относительная толщина которой $\chi<0.06$. В процессе диффузионного соединения в твердой фазе одновременно идет спекание порошковой никелевой прослойки и формирование переходной зоны между прослойкой и сталью. Переходная зона состоит из твердого раствора никеля в $\alpha$-Fe и упорядоченного твердого раствора железа в никеле $\left(\mathrm{FeNi}_{3}\right)$.

DOI: 10.21883/JTF.2018.02.45409.2325

\section{Введение}

Диффузионное соединение однородных и разнородных материалов, компоненты которых обладают взаимной диффузией при твердофазных реакциях, обеспечивает комплекс свойств, которые невозможно получить при использовании других способов соединения деталей и узлов различных форм и размеров [1-3]. Применение температуры $0.4-0.8 T_{m}$ (где $T_{m}$ - температура плавления наиболее легкоплавкого из соединяемых материалов) исключает образование ликваций, рекристаллизацию, уменьшает остаточные напряжения и пластическую деформацию. Диффузионное соединение образуется в результате деформационного воздействия на соединяемые материалы, имеющие поверхности с определенной шероховатостью (физический контакт на основе межатомного взаимодействия), активации контактных поверхностей (образование активных центров на поверхности более твердого из соединяемых металлов), объемного взаимодействия (протекает на активных центрах, сопровождается релаксацией напряжений) $[2,4,5]$. Твердофазные диффузионные процессы, протекающие в соединении материал-прослойка-материал, носят сложный и комплексный характер, определяются свойствами соединяемых материалов, их чистотой, шероховатостью поверхности, составом, способом нанесения и толщиной прослойки, параметрами режима сварки и т. д. Требуемая прочность соединений обеспечивается формированием переходной зоны с образованием общих зерен в области контакта зависит от свойств соединяемых материалов и образующихся в диффузионной зоне фаз [4].

Дальнейшее развитие существующих методов интенсификации процесса диффузионной сварки, позволяющих получать качественные соединения при более низких температурах $-0.3-0.6 T_{m}$, может быть связано с применением промежуточных прослоек [6-11]. Диффузионное соединение через промежуточную прослойку позволяет значительно уменьшить температуру изотермической выдержки и сварочное давление, а также исключить возможность образования интерметаллидов в переходной зоне соединения, снизить химическую неоднородность, термодинамическую нестабильность, термодеформационное воздействие на свариваемые материалы и детали. С этой точки зрения может быть получен хороший результат при использовании промежуточных прослоек, спрессованных из субмикронных и наноразмерных порошков [3,7,12].

Целью настоящей работы является исследование формирования микроструктуры, элементного состава фаз и свойств диффузионного соединения стали 45, полученного через прессованную прослойку из субмикронного порошка никеля, результаты которого позволят прогнозировать получение соединения с требуемыми свойствами $[9,13]$.

\section{Объекты и методики исследований}

Для изготовления слоистых композитов сталь 45-прессованная порошковая прослойка $\mathrm{Ni}$-сталь 45 были использованы цилиндрические образцы из стали 45 (элементный состав: 0.45 wt.\% C, 0.2 wt.\% Si, 0.7 wt.\% Mn, 0.25 wt.\% Cr, 0.04 wt.\% S 0.035 wt.\% P, остальное - Fe). Диффузионное соединение образцов проводили через активирующую прослойку. В качестве прослойки применили прессовки из субмикронного порошка Ni (средний размер частиц $100 \pm 20 \mathrm{~nm}$, форма - близкая к сферической), полученного восстановлением гидразингидратом хлорида никеля из сильнощелочных водных растворов [14]. Прослойку получали прессованием навески 

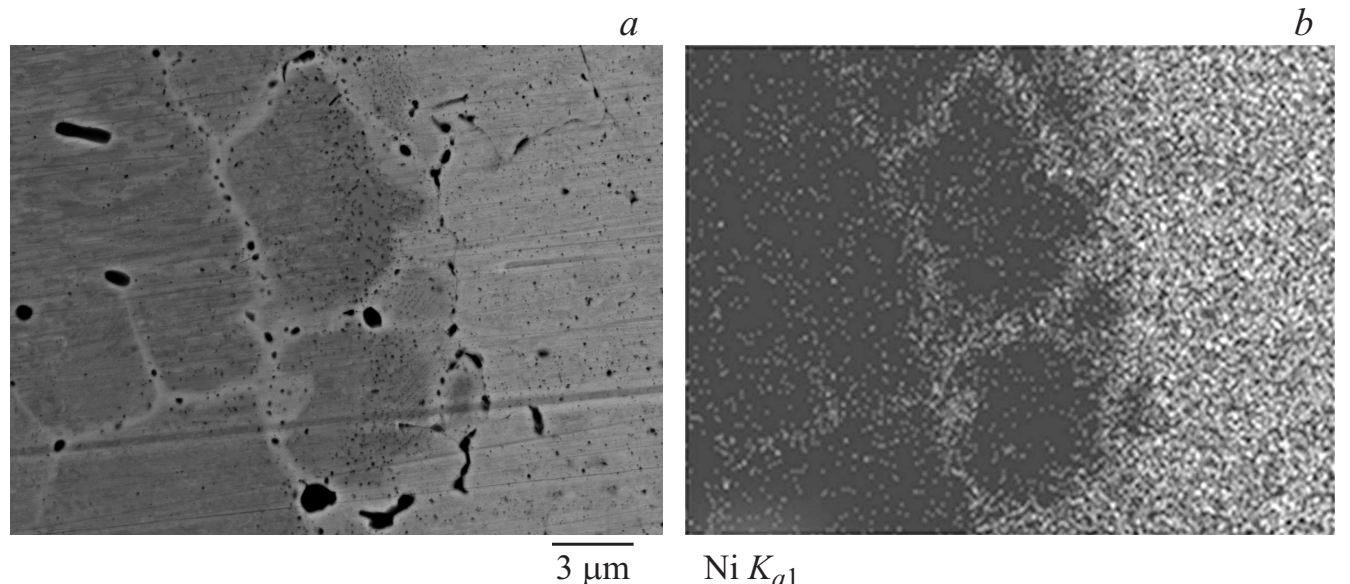

Ni $K_{a 1}$

Рис. 1. Электронно-микроскопическое изображение микроструктуры диффузионного соединения образца (слева - сталь 45, справа - прослойка $\mathrm{Ni})$, полученного через прослойку $\left(P_{\text {press }}=600 \mathrm{MPa}\right): a-$ в композиционном контракте; $b-$ в характеристическом рентгеновском излучении Ni.
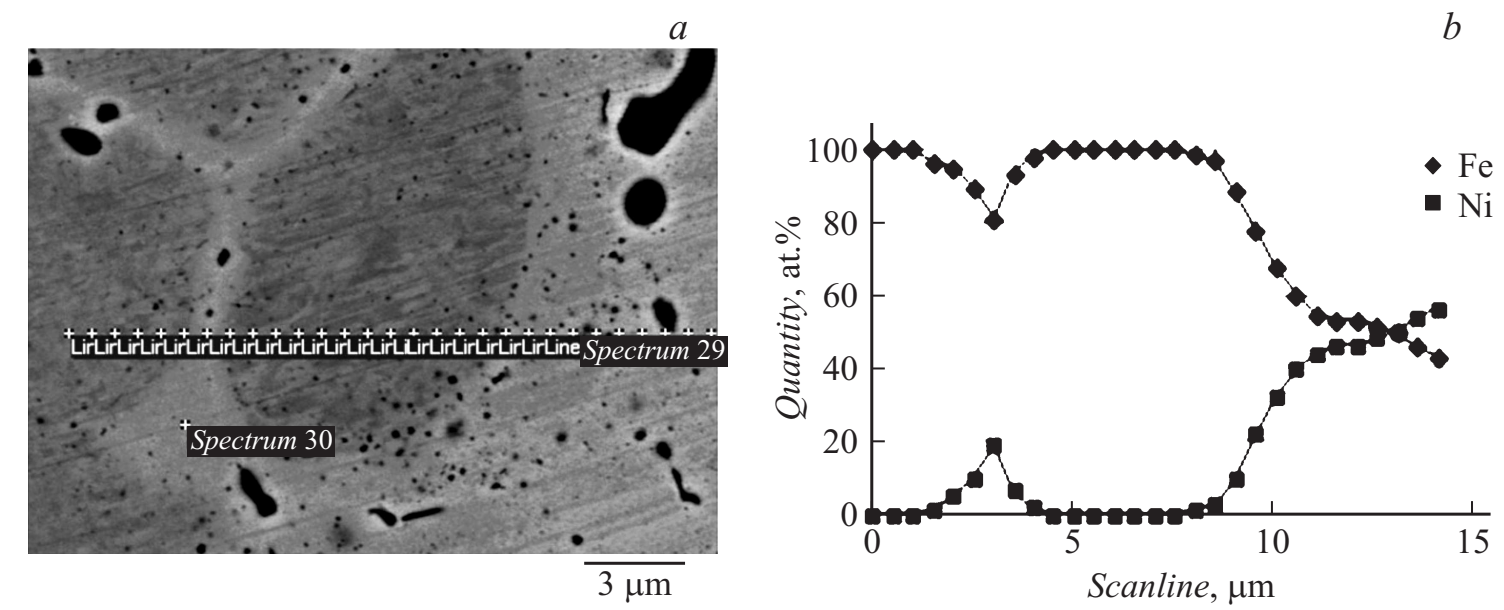

Рис. 2. Электронно-микроскопическое изображение (a) микроструктуры образца сталь 45-прослойка, полученного через прессованную прослойку $\left(P_{\text {press }}=600 \mathrm{MPa}\right)$ : концентрационные кривые $(b)$ распределения химических элементов по линии сканирования состава.

порошка массой $0.125 \mathrm{~g}$ в жесткой матрице. Для определения оптимальных условий получения качественного диффузионного соединения давление прессования $P_{\text {press }}$ варьировали в диапазоне от 100 до $900 \mathrm{MPa} \mathrm{c} \mathrm{шагом}$ $100 \mathrm{MPa}$. Толщина прессовок составляла $250 \pm 20 \mu \mathrm{m}$, остаточная пористость варьировала от 35 до 60\%.

Соединяемые поверхности стальных образцов имели исходную шероховатость $0.5 \mu \mathrm{m}$ (по шкале $R a$ ). Образцы были соединены в сборку сталь 45 - прессовка $\mathrm{Ni}$ сталь 45 и помещены в специальное приспособление, позволяющее реализовать давление в процессе нагрева и изотермической выдержки. Диффузионное соединение образцов проведено в вакуумной установке при сварочном давлении $10 \mathrm{MPa}$, времени изотермической выдержки $20 \mathrm{~min}$, температуре $1123 \mathrm{~K}$ (что составляет $\approx 0.6$ от $T_{m}$ никеля), вакууме $10^{-3} \mathrm{~Pa}$.
Исследование микроструктуры поперечных шлифов слоистых композитов и определение элементного состава порошковой прослойки и диффузионных соединений проведены с помощью методов сканирующей электронной микроскопии и энергодисперсионного микроанализа на сканирующем электронном микроскопе JEOL JSM$7001 \mathrm{~F}$ с системой энергодисперсионного анализа (EDS спектрометр Inca PentaFetx3) и JEOL JSM 6490LV.

Определение микротвердости проводили на приборе ПМТ-3 нанесением царапины ребром четырехгранной алмазной пирамиды под действием нормальной нагрузки, равной $0.02 \mathrm{~N}$, на поверхностный слой шлифа через зону диффузионного соединения [15]. Микротвердость рассчитывали по формуле $H_{\mu}=3.708 P / b^{2}$, где $P$ нормальная нагрузка, $N ; b-$ ширина царапины, $\mathrm{mm}$. 


\section{Результаты и обсуждение}

Соединение образцов стали проводили через прессованную прослойку из порошка никеля, отношение толщины $(h, \mathrm{~mm})$ которой к диаметру $(d, \mathrm{~mm})$ было равно $\chi=h / d=0.25 / 9=0.028$. Как известно [4], если прослойка имеет относительную толщину $\chi<0.06$, то разрушение образца идет не по прослойке, а по одному из соединяемых материалов, что свидетельствует о том, что получено равнопрочное диффузионное соединение.

Диффузионное соединение образцов стали через прессованную прослойку из порошка никеля образуется вследствие формирования в результате твердофазной реакции общих зерен в переходной зоне между соединяемыми разнородными материалами и спекания порошковой прослойки. Этот процесс приводит к изменению микроструктуры и распределению химических элементов по диффузионному соединению. Прослойка в процессе твердофазного взаимодействия при $T=1123 \mathrm{~K}$ оказывает активирующее влияние вследствие вклада избыточной энергии, связанной с возможностью образования общей фазы - твердого раствоpa $\mathrm{Fe}-\mathrm{Ni}$, а также энергии, обусловленной наличием дефектов и развитой поверхностью субмикронных частиц никеля. В низкотемпературной области при содержании менее 60 at.\% Ni формируются и существуют фазы - $\alpha$-Fe + упорядоченная фаза $\mathrm{FeNi}_{3}$, а при более 60 at.\% $\mathrm{Ni}+$ упорядоченная фаза $\mathrm{FeNi}_{3}$ (твердый раствор) [16].

Электронно-микроскопическое изображение типичной микроструктуры переходной зоны, представленное на рис. 1, $a$, получено с применением метода композиционного контраста (в обратно отраженных электронах).

Таблица 1. Элементный состав фаз, at.\%

\begin{tabular}{c|c|c}
\hline Линия спектра & $\mathrm{Fe}$ & $\mathrm{Ni}$ \\
\hline 1 & 100.00 & - \\
2 & 100.00 & - \\
3 & 100.00 & - \\
4 & 98.48 & 1.52 \\
5 & 95.06 & 4.94 \\
6 & 89.72 & 10.28 \\
7 & 81.08 & 18.92 \\
8 & 93.24 & 6.76 \\
9 & 98.08 & 1.92 \\
10 & 100.00 & - \\
11 & 100.00 & -
\end{tabular}

Таблица 2. Элементный состав фаз, at.\%

\begin{tabular}{c|c|c|c}
\hline Спектр & $\mathrm{O}$ & $\mathrm{Fe}$ & $\mathrm{Ni}$ \\
\hline 1 & 11.69 & 88.30 & - \\
2 & - & 100.00 & - \\
3 & 48.92 & 48.52 & - \\
4 & 9.11 & 88.74 & 2.55
\end{tabular}

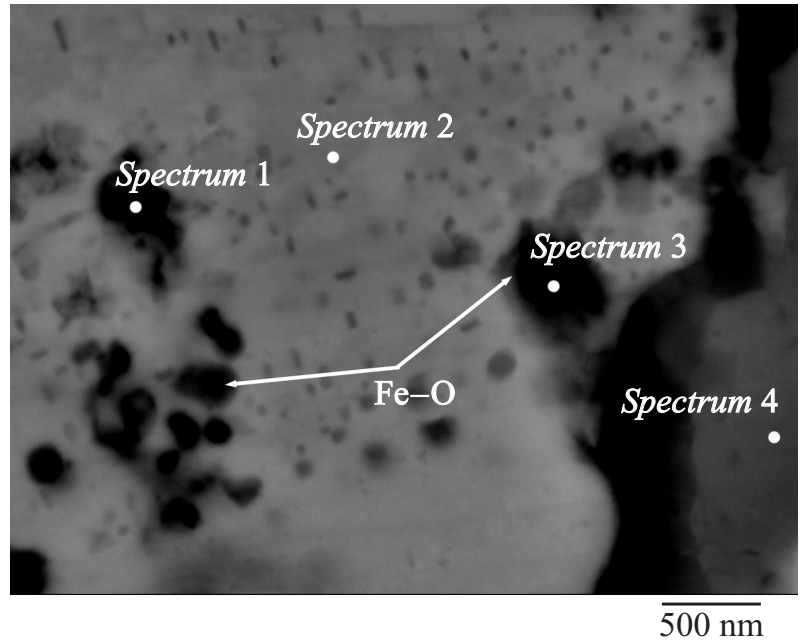

Рис. 3. Электронно-микроскопическое изображение прослойки, образовавшейся вокруг зерен феррита в зоне диффузионного соединения, с маркерами спектров.

При использовании данного метода получения на изображении фаз, в состав которых входят более тяжелые элементы, имеют светло-серый цвет, легкие - темносерые. Изображение, полученное в характеристическом рентгеновском излучении никеля (рис. $1, b)$, показывает область распределения никеля, совпадающую со светлой прослойкой вокруг темных зерен в диффузионном соединении (рис. 1,a).

Структуру стали формируют две фазы: феррит (твердый раствор углерода в $\alpha$-Fe) и цементит $\left(\mathrm{Fe}_{3} \mathrm{C}\right)$. Диффузия никеля по границам зерен железа (феррита) подтверждается результатами энергодисперсионного микроанализа, по данным которого строились соответствующие концентрационные зависимости (рис. 2, b). Получен элементный состав в точках, расположенных на линии, пересекающей зерно феррита, и светлые области вокруг него, расположенные в зоне диффузионного соединения (рис. 2, $a$ ). На рис. 2, $b$ изображены концентрационные кривые распределения химических элементов по линии сканирования состава, состоящей из 28 точечных спектров. В табл. 1 представлен элементный состав, полученный по линии сканирования с шагом $0.5 \mu \mathrm{m}$.

Спектры 1-3 и 10, 11 соответствуют ферриту (железо), спектры 4-9 показывают наличие железа и никеля в прослойке, расположенной по границам зерен феррита. Процесс образования межзеренных прослоек вследствие поверхностной диффузии никеля по границам зерен железа [17] обусловлен тем, что никель является поверхностно-активным по отношению к железу — поверхностная энергия никеля $\left(2.364 \mathrm{~J} / \mathrm{m}^{2}\right)$ меньше поверхностной энергии железа $\left(2.939 \mathrm{~J} / \mathrm{m}^{2}\right)$ [18]. Как следует из концентрационных кривых распределения элементов в переходной зоне (рис. 2, $b$ ) и электронномикроскопических изображений (рис. $1, b, 2, a)$, диффузионное соединение в области стали образуется вследствие диффузии никеля в сталь по границам зерен 
$a$
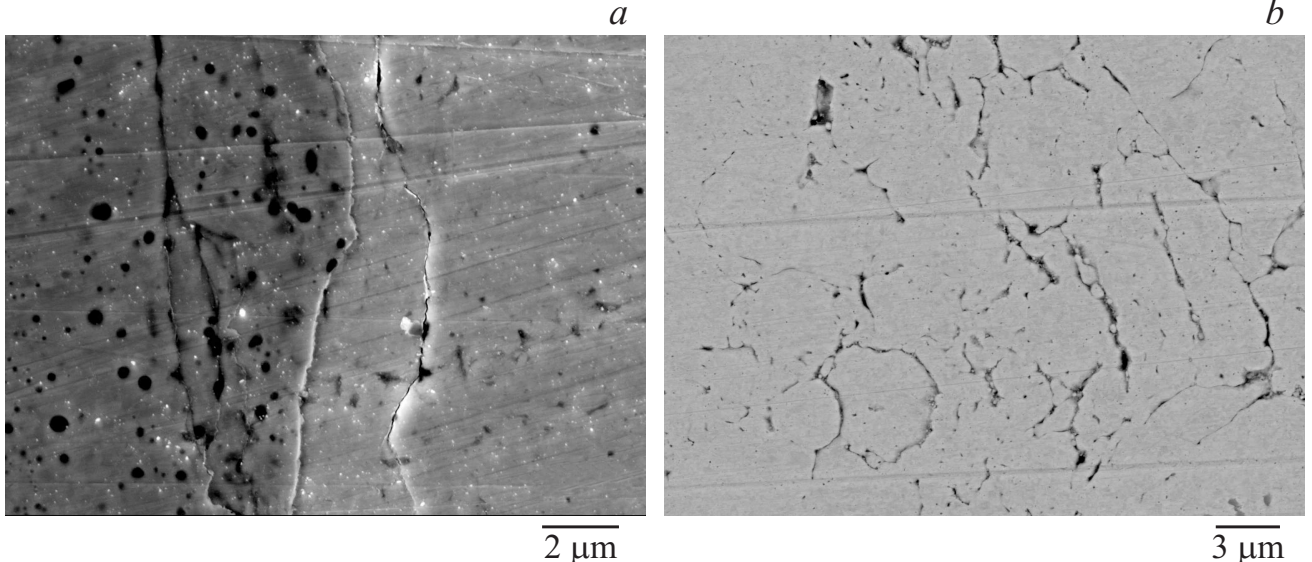

Рис. 4. Электронно-микроскопическое изображение спеченной порошковой прослойки, $P_{\text {press }}=600 \mathrm{MPa:} a-$ продольные трещины; $b$ - поры и несплошности по границам зерен.
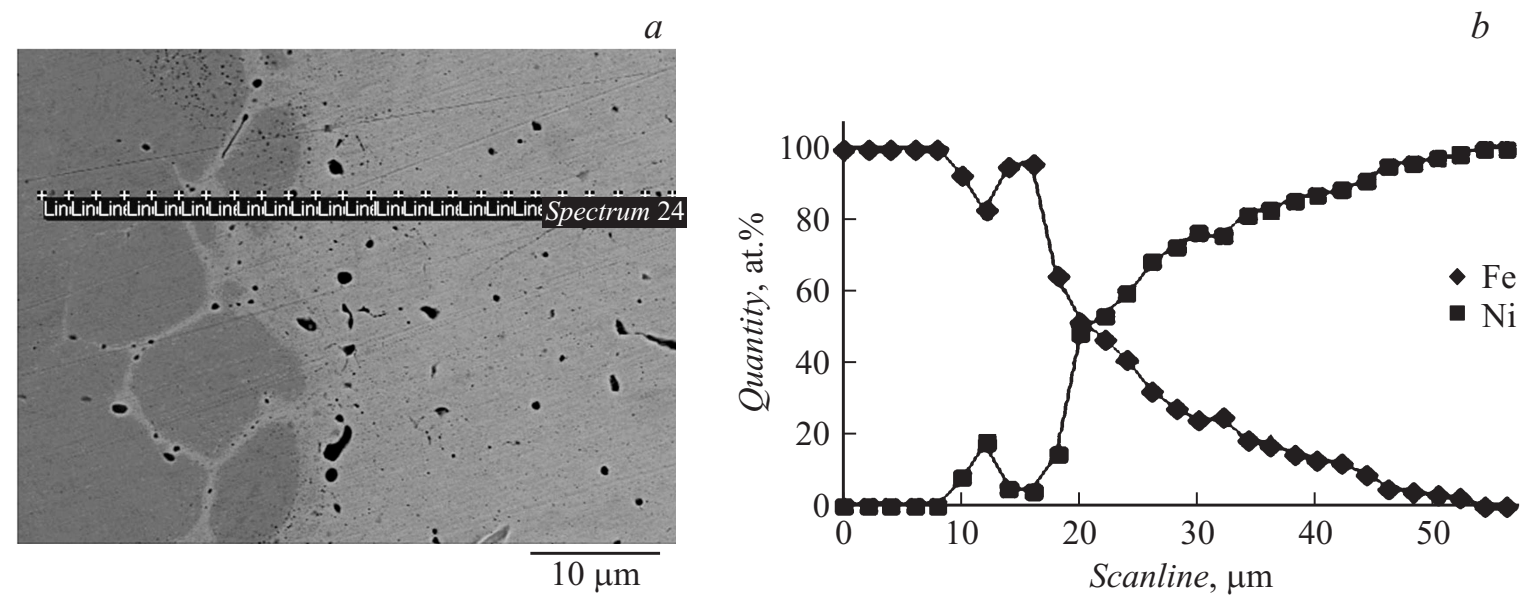

Рис. 5. Электронно-микроскопическое изображение диффузионного соединения: $a$ - переходная зона; $b-$ концентрационные кривые распределения химических элементов.

феррита и формирования общих зерен. Анализ микроструктуры позволил выявить наличие в диффузионном соединении как со стороны стали, так и со стороны никеля отдельные включения черного цвета (рис. $1, a, 3)$. Исследование методом энергодисперсионного микроанализа элементного состава включений, расположенных по границам зерен феррита в стали, показывает наличие в их составе железа и кислорода (табл. 2, спектры 1 и 3). Появление оксидных фаз может быть связано с тем, что адсорбированные на поверхностях образцов газовые пленки после образования фактического контакта между соединяемыми поверхностями удаляются путем растворения в основном металле при диффузионном соединении. Этому процессу способствует повышенная дефектность в зоне соединения, обусловленная предварительной механической обработкой поверхностей и пластической деформацией микровыступов при термодеформационном воздействии, что определяет также и повышенные скорости диффузии. Как показал Т.Эндзе, температура, при которой электросопротивление окис- ленной поверхности соединения становится равной электросопротивлению основного металла, в данном случае железа, составляет $1073 \mathrm{~K}$ [14]. Температура получения диффузионного соединения стали и никеля равна $1123 \mathrm{~K}$, следовательно, идет диффузия кислорода внутрь соединяемых материалов, вследствие чего образуются оксидные фазы в прослойках, образованных вокруг зерен феррита (рис. 1, $a, 3$ ).

Исследование микроструктуры спеченной порошковой прослойки показало наличие продольных трещин (рис. $4, a)$, образовавшихся при давлении прессования 800 и $900 \mathrm{MPa}$, что свидетельствует о превышении оптимального давления прессования никеля и приводит к расслою прессовки. Кроме того, выявлены дефекты в порошковой прослойке, в которой наблюдается определенная форма зерен и их ориентация. Наличие по границам зерен пор и несплошностей в прослойке, полученной прессованием при высоких давлениях, связано с тем фактом, что порошковое тело с большей относительной плотностью характеризуется большим коэффициентом 


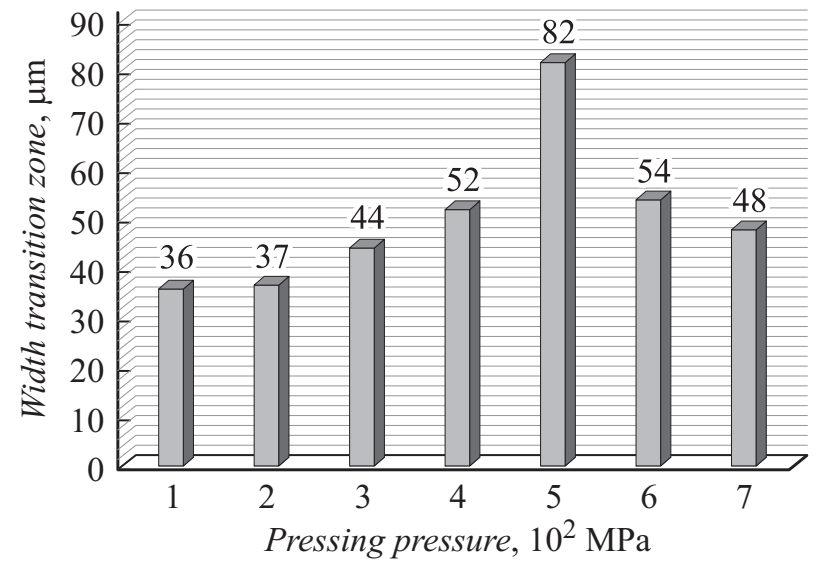

Рис. 6. Зависимость ширины переходной зоны от давления прессования прослойки.

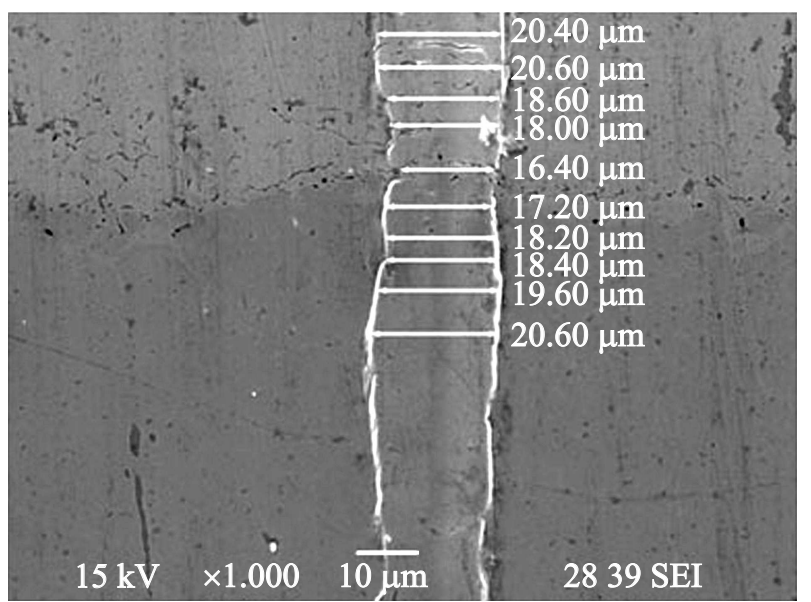

Pис. 7. Типичная микроструктура и общий вид царапины с замерами ширины, проведенной для расчета микротвердости образца $\left(P_{\text {press }}=600 \mathrm{MPa}\right)$.

вязкости, что затрудняет усадку в процессе спекания и приводит к образованию таких дефектов (рис. 4, b) [17].

Типичная микроструктура переходной зоны и общий вид распределения химических элементов в диффузионном соединении образца, полученного через порошковую прослойку никеля $\left(P_{\text {press }}=600 \mathrm{MPa}\right)$, представлены на рис. 5, $b$. Анализ концентрационных кривых (рис. $5, b$ ) показывает, что по мере удаления от границы соединения в глубину никелевой прослойки наблюдается монотонное уменьшение количества железа и увеличение количества никеля. Диффузия железа в порошковую прослойку происходит по объему зерен никеля, диффузии никеля в сталь - по границам зерен железа, появление таких общих зерен формирует переходную зону. Диффузия железа в никель идет более активно и на большую глубину $-34 \mu \mathrm{m}$, никеля в железо $-20 \mu \mathrm{m}$. Ширина переходной зоны определялась по концентрационным кривым (рис. 5,b), для данного образца она составляет $54 \mu \mathrm{m}$.
Ширина переходной зоны растет с увеличением давления прессования прослойки и при $P_{\text {press }}=500 \mathrm{MPa}$ составляет $82 \mu \mathrm{m}$, при дальнейшем увеличении давления прессования уменьшается (рис. 6). Из этого следует, что формирование переходной зоны идет более активно в образцах, прослойка которых получена при $P_{\text {press }}$ от 400 до $600 \mathrm{MPa}$. Также следует отметить, что в этих образцах процесс спекания прессованной прослойки активизируется вследствие ее остаточной пористости $(\approx 42 \%)$. Оптимальным давлением для получения прессованной прослойки с точки зрения формирования качественного диффузионного соединения следует принять $P_{\text {press }}=500 \mathrm{MPa}$.

Анализ полученных значений микротвердости образцов после термодеформационного воздействия показал, что она не зависит от давления прессования порошковой прослойки. На рис. 7 представлены типичная микроструктура и общий вид царапины с замерами ширины, проведенной для расчета микротвердости образца $\left(P_{\text {press }}=300 \mathrm{MPa}\right)$. Микротвердость стали составляет $1.80-2.00 \mathrm{GPa}$; спеченной порошковой прослойки $\mathrm{Ni}-$ $1.75-1.90 \mathrm{GPa}$; переходной зоны - 2.20-2.50 GРa. Увеличение микротвердости переходной зоны объясняется тем, что она образована упорядоченным твердым раствором $\mathrm{Fe}-\mathrm{Ni}$, имеющим механические свойства выше, чем чистые металлы.

\section{Заключение}

С помощью метода диффузионной сварки получены слоистые композиты из стали 45 через порошковую прослойку, спрессованную при различных давлениях. Диффузионное соединение образцов стали 45 через прессованную прослойку из порошка никеля формируется при содержании никеля < 60 at.\% фазами $\alpha$ - $\mathrm{Fe}+$ упорядоченная фаза $\mathrm{FeNi}_{3}$, а при > 60 at.\% $\mathrm{Ni}+$ упорядоченная фаза $\mathrm{FeNi}_{3}$. Выявлено, что поверхностная диффузия никеля по границам зерен железа обусловливает образование межзеренных прослоек, диффузия железа в никель идет по объему зерна никеля. Полученные значения микротвердости переходной зоны выше, чем микротвердость железа и никеля, что подтверждает формирование в диффузионном соединении твердых растворов Fe-Ni. Выявлена зависимость ширины переходной зоны от давления прессования прослойки. Определено, что оптимальным значением, с точки зрения формирования качественного диффузионного соединения и процесса спекания прослойки является давление прессования прослойки, равное $500 \mathrm{MPa}$.

\section{Список литературы}

[1] Казаков Н.Ф. Диффузионная сварка материалов. М.: Машиностроение, 1976. 312 с.

[2] Каракозов Э.С. Сварка металлов давлением. М.: Машиностроение, $1986.280 \mathrm{c}$. 
[3] Люшинский А.В. Диффузионная сварка разнородных материалов. М.: Издательский центр Академия, 2006. 208 с.

[4] Конюшков Г.В., Мусин Р.А. Специальные методы сварки давлением. Саратов: Ай Пи Эр Медиа, 2009. 632 с.

[5] Булков А.Б., Пешков В.В., Петренко В.Р. и др. // Сварочное производство. 2011. № 11, С. 18-24.

[6] Бойко Н.В., Хазов И.А., Селезнева Л.В. и др. // Металловедение и термическая обработка металлов. 2012. № 9. C. 51-55.

[7] Зеер Г.М., Зеленкова Е.Г., Белоусов О.В. и др. // ЖТФ. 2015. Т. 85. Вып. 4. С. 46-51.

[8] Люшинский А.В. // Сварка и диагностика. 2009. № 4. C. $42-44$.

[9] Ustinov A., Falchenko Yu., Melnichenko T. et al. // J. Mater. Proces. Technol. 2013. Vol. 213. P. 543-552.

[10] Устинов А.И., Фальченко Ю.В., Мельниченко Т.В. и др. // Автоматическая сварка. 2015. № 7. С. 5-11.

[11] Люшинский А.В., Федорова Е.С., Старовачкий С.В. и др. // Авиакосмическое приборостроение. 2015. № 6. C. 3-7.

[12] Ющенко К.А., Задерий Б.А., Звягинцева А.В. и др. // Автоматическая сварка. 2006. № 11. С. 3-10.

[13] Zhang J., Shen Q., Luo G. et al. // Mater. Design. 2012. Vol. 39. P. 81-86.

[14] Enjo T., Ikeuchi K., Akikawa N. // J. Jpn. Weld Soc. 1982. Vol. 51. N. 3. P. 272-279.

[15] ГОСТ 21318-75. Измерение микротвердости царапанием алмазными наконечниками. М.: Изд-во стандартов, 1988. $28 \mathrm{c}$.

[16] Диаграммы состояния двойных металлических систем. Справочник: В 3-х т. Т. 2 / Под общ. ред. Н.П. Лякишева. М.: Машиностроение, 1996. 992 с.

[17] Либенсон Г.А., Лопатин В.Ю., Комарицкий Г.В. Процессы порошковой металлургии. В 2-х т. Т. 2. Формование и спекание. М.: МИСИС, 2002. 320 с.

[18] Mezey L.Z., Giber J. // Jpn. J. Appl. Phys. 1982. Vol. 21. P. 1569-1571. 